\title{
RECEPC]A ŚREDNIOWIECZNYCH MOTYWÓW W ŚWIECIE GWIEZDNYCH WOJEN
}

Małgor zata DELIMATA-PROCH

\section{ABSTRACT}

\section{RECEPTION OF THE MEDIEVAL MOTIFS IN THE WORLD OF STAR WARS}

The paper makes up an attempt to systematize and occasionally verify the views on the medieval motifs which were to be used while creating the world of Star Wars. The synchronic method applied in various publications lies behind opinions according to which the inspiration here included: Arthurian legends, the medieval concept of minne, visions of hell, the history and tradition of the Knights Templar, as well as the samurai in feudal Japan. These opinions cannot be regarded as entirely grounded. The remarks on the reception of some motifs related to the samurai or the Knights Templar seem justified as well as the plot of courtly love and the medieval image of hell. However, insistent juxtaposing, among others, of the individual stages of the lives of the saga's main characters with the fortunes of king Arthur is controversial.

\section{KEYWORDS:}


Zagadnienie granicy pomiędzy rzeczywistością historyczną a fikcją proponowaną przez twórców współczesnej kultury wydaje się nieobce przedstawicielom rozmaitych dyscyplin. Niejednokrotnie formułowano poglądy na temat recepcji obszarów wiedzy historycznej, w tym poszczególnych motywów pochodzących z literatury średniowiecznej, czy losów postaci, a także odnoszono się do filmowych interpretacji rzeczywistości przeszłej. Te studia prowadzono dwojako, czyli synchronicznie i diachronicznie: z jednej strony, badano jedynie przenikanie obu sfer - świata historii i świata fikcji (mediewalizm genealogiczny) - z drugiej natomiast, analizowano wpływ aktualnej sytuacji politycznej czy społecznej na kreowany obraz .

To opracowanie wpisuje się poniekąd w wymienione nurty. Warto nadmienić, że pełne wyeksplorowanie proponowanego zagadnienia w ramach niniejszego tekstu okazuje się niemożliwe ze względu na oczywiste ograniczenia. Uniwersum Gwiezdnych wojen wykreowano nie tylko w ekranizacjach, ale także w licznych powieściach, komiksach oraz grach komputerowych. Ten olbrzymi zbiór danych winien stanowić podstawę szeroko zakrojonych studiów analityczno-porównawczych, zatem wspomniane opracowanie może być jedynie skromnym przyczynkiem. W jego ramach uwzględniono sporą część średniowiecznych motywów, które zainspirowały twórców, natomiast ograniczono analizę światopoglądu autorów czy zjawisk stymulujących kreowanie obrazu.

Studia nad obecnością historii średniowiecznej w uniwersum Gwiezdnych wojen prowadzono intensywnie, i to głównie na zachodzie Europy oraz w Stanach Zjednoczonych. Od końca lat siedemdziesiątych XX wieku głos w powyższej kwestii zabierali uczeni, dziennikarze, a w dobie Internetu sami fani². Należy dodać, że

1 Przykładowo: J. Aberth, A Knight at the Movies: Medieval History on Film, New York 2003; A. Alexandridis, Die Frauen des römischen Kaiserhauses. Eine Untersuchung ihrer bildlichen Darstellung von Livia bis Iulia Domna, Mainz 2004; A. Bernau, B. Bildhauer, Medieval Film, Manchester 2011; B. Bildhauer, Filming the Middle Ages, London 2011; Classical Myth \& Culture in the Cinema, ed. by J. Solomon, Oxford 2001; Classics and Cinema, ed. by M. Winkler, Lewisburg-London-Toronto 1991; A. Elliott, Remaking the Middle Ages: the Methods of Cinema and History in Portraying the Medieval World, Jefferson 2011; Film and Fiction Reviewing the Middle Ages, ed. by T. Shippey, Cambridge 2002; L.A. Finke, M.B. Shichtman, Cinematic Illumination: the Middle Ages on Film, Baltimore 2010; N. Haydock, Movie Medievalism: the Imaginary Middle Ages, Jefferson 2008; Hollywood and History. Costume Design in Film, hrsg. von E. Maeder, Los Angeles-London 1987; Imperial Projections. Ancient Rome in Modern Popular Culture, ed. by S.R. Joshel, M. Malamud, D.T. McGuire, Baltimore 2001; M. Lindner, Rom und seine Kaiser im Historienfilm, Frankfurt am Main 2007; Medieval Hero on Screen: Representations from Beowulf to Buffy, ed. by M.W. Driver, Jefferson 2004; Mittelalter im Film, hrsg. von Ch. Kiening, Berlin 2006; J. Solomon, The Ancient World in Cinema, New Haven-London 2001; S. Walker, P. Higgs, Cleopatra of Egypt: From History to Myth, Princeton 2001; D. Wenzel, Kleopatra im Film. Eine Königin Ägyptens als Sinnbild für orientalische Kultur, Remscheid 2005.

Przykładowo: T. Henthorne, Boys to Men: Medievalism and Masculinity in "Star Wars" and "E.T.: The ExtraTerrestrial" [w:] Medieval Hero on Screen: Representations from Beowulf to Buffy, ed. by M.W. Driver, Jefferson 2004, 
metoda synchroniczna zastosowana $\mathrm{w}$ tych tekstach miała ujawnić nieskomplikowaną recepcję motywów średniowiecznych, które ubogaciły samą fabułę (motywy pochodzące z cyklu arturiańskiego czy motywy dworskiej miłości, kasaty templariuszy oraz średniowiecznego piekła), a dodatkowo posłużyły tworzeniu obrazu Jedi jako formacji bliskiej templariuszom czy samurajom $\mathrm{z}$ feudalnej Japonii ${ }^{3}$. Warto jeszcze nadmienić, że nie wszystkie wspomniane teksty były równie wartościowe poznawczo, zatem tym bardziej czas ku temu, aby pomimo rzeczonych ograniczeń usystematyzować te obserwacje.

\section{CYKL ARTURIAŃSKI}

Peter Konieczny odnotowal, że wkrótce po premierze Nowej nadziei zwrócono uwagę na obecność wątków arturiańskich w ekranizacji ${ }^{4}$ Tych opinii jak dotąd nie zweryfikowano. Co więcej, także w XXI wieku wiele osób formułowało poglądy na temat recepcji prawie in extenso losów bohaterów legend arturiańskich oraz motywu miecza $^{5}$. W ramach tego pierwszego obszaru zwracano uwagę między innymi na liczne analogie pomiędzy królem Arturem a Lukiem, jego ojcem Anakinem czy Rey

s. 73-93; N. Jamilla, Sword Fighting in the "Star Wars" Universe, Jefferson 2008; T. MacMullan, Elegant Weapons for Civilized Ages: The Jedi and Warrior-Monks throughout History [w: ] Star Wars and History, ed. by N.R. Reagin, J. Liedl, Hoboken 2013, s. 67-98; G. Morgan, The Holy Grail: From Antiquity to the Present Day, Harpenden 2015; E. OrtegaArjonilla, A. Belén Martínez-López, Looking for the Lost Paradise: Cultural Diversity, Translation and Film Adaptation in the Contemporary Dissemination of Medieval Culture, Stereotype and Values (Eco, Tolkien, Chrétien de Troyes, Follet and Lucas) [w:] New Medievalisms, ed. by J. Martín-Párraga, J. de Dios Torralbo-Caballero, Cambridge 2015, s. 179-238; Star Wars/Arthurian Legend Comparison Tale [online], 2013 [dostęp: 4 maja 2017]. Dostępny w World Wide Web: www.angelfire.com/vi/knight_1192/SW/SW_theories/SWAL.html; Are the Jedi based upon the Samurai? [online], 2014 [dostęp: 4 maja 2017]. Dostępny w World Wide Web: forums.obsidian.net/topic/14289-are-the-jedi-basedupon-the-samurai/; P. Konieczny, Star Wars and the Middle Ages [online], 2014 [dostęp: 4 maja 2017]. Dostępny w World Wide Web: www.medievalists.net/2014/03/star-wars-middle-ages/; J. Man, Sword vs. Lightsaber: How the Samurai Warriors Inspired Jedi Knights [online], 2015 [dostęp: 4 maja 2017]. Dostępny w World Wide Web: www. salon.com/2015/12/19/sword_vs_lightsaber_how_the_samurai_warriors_inspired_the_jedi_knights/; W. Williams, Love and Star Wars: The Tragedy of Anakin and Padme [online], 2015 [dostęp: 4 maja 2017]. Dostępny w World Wide Web: www.thegeekblock.com/455/; D. Pahman, The Jedi Knights Templar [online], 2016 [dostęp: 4 maja 2017 ]. Dostępny w World Wide Web: https://action.org/pub/commentary/2016/01/13/jedi-knights-templar; Juliwitte, Star Wars meets Arthuriana: Anakin and Padme [online], 2016 [dostęp: 4 maja 2017]. Dostępny w World Wide Web: https://clonecorridor.wordpress.com/2016/01/16/star-wars-meets-the-arthuriana-anakin-and-padme/; Studying Skywalkers: Excalibur and the Lightsaber [online], 2016 [dostęp: 4 maja 2017]. Dostępny w World Wide Web: www. starwars.com/news/studying-skywalkers-excalibur-and-the-lightsaber.

3 W tej refleksji uwzględniono sporą część średniowiecznych motywów. Pominięte sygnalizowano w przypisach.

P. Konieczny, dz. cyt.; oprócz odnotowanych w tej refleksji warto wymienić nieuwzględnione: analogie do Okrągłego Stołu, inspiracje postaciami Lancelota i Parsifala, konstrukcja opowieści oparta na schemacie legend arturiańskich: E. Ortega-Arjonilla, A. Belén Martínez-López, dz. cyt., s. 231-232; por. Juliwitte, dz. cyt.

Przykładowo: A.J. Weisl, The Persistence of Medievalism: Narrative Adventures in Public Discourse, Basingstoke 2003; E. Ortega-Arjonilla, A. Belén Martínez-López, dz. cyt., s. 224-233. 
z Przebudzenia Mocy ${ }^{6}$ Zdaniem znawców problematyki losy trzech ostatnich postaci nawiązywały do arturiańskiego wzorca bohatera, którego przeszłość została po części owiana mgłą tajemnicy. Dodajmy, że z rozmaitych wersji arturiańskich opowieści wyłonił się spójny obraz, zgodnie z którym sam król Artur został poczęty w na poły mistycznych okolicznościach. W ten akt - oprócz rodziców (Uthera i Igreny) - był zaangażowany także Merlin, który dzięki magicznym zabiegom umożliwił Utherowi spędzenie nocy z wybranką. Dziecko wtedy poczęte zostało oddane Merlinowi zaraz po urodzeniu, a po kilkunastu latach doświadczyło zdarzenia utożsamionego z dwojakim przełomem: młody Artur okazał się wybrańcem, który finalnie pokonał wrogów i ocalił poddanych. Mowa tu o słynnym mieczu, który przyszły król wyciągnął z kamienia. Sam ten akt, z jednej strony, legitymizował prawa syna do schedy po ojcu, natomiast z drugiej, ujawnił niepospolite predyspozycje oraz przeznaczenie tego pierwszego .

Zdaniem poszukiwaczy arturiańskich inspiracji Gwiezdnych wojen wspomniana opowieść stanowiła niejako matrycę, przy pomocy której odwzorowano losy Luke’a, Anakina oraz Rey. Ten schemat tworzyły: tajemnicze poczęcie, rozłąka z rodzicami, ujawnienie predyspozycji dzięki artefaktowi oraz misja.

- Poczęcie: sam Anakin został powołany na świat być może przez midichloriany. Shmi, matka chłopca, nie tyle nie znała tożsamości ojca dziecka, ile twierdziła, że takiego w ogóle nie było. Anakin miał dwojakie predyspozycje - posiadał zdolności techniczne, a także wysokie stężenie midichlorianów, co przykuło uwagę Qui-Gon Jinna. Właśnie z tego powodu rycerz Jedi podjął decyzję o wywiezieniu chłopca $\mathrm{z}$ Tatooine oraz poddaniu go szkoleniu ${ }^{8}$.

- Rozłąka z rodzicami: tego doświadczyli wszyscy wymienieni bohaterowie Gwiezdnych wojen. Luke został oddany krewnym ze strony ojca zaraz po urodzeniu. To Obi-Wan Kenobi podjął decyzję o rozdzieleniu bliźniąt, a po kilkunastu latach odegrał rolę w ujawnieniu Mocy Luke’a oraz jego szkoleniu. Ta kreacja losów Obi-Wan Kenobiego legła u podstaw identyfikacji tej postaci z Merlinem. Sam Luke odkrył własne korzenie dopiero w wieku młodzieńczym ${ }^{9}$.

O uwarunkowaniach politycznych, które wpłynęły na kreację postaci Luke’a i Lei oraz recepcję motywów arturiańskich: T. Henthorne, dz. cyt., s. 79-81.

Historię króla Artura wielokrotnie redagowano (także w XX w.): S. Undset, Legendy o królu Arturze i Rycerzach Okrąłego Stołu, tłum. B. Hłasko, Warszawa 1957, s. 5-16; Opowieści Okragłego Stołu, oprac. J. Boulenger, tłum. K. Dolatowska, T. Komendant, wstęp E.D. Żółkiewska, Warszawa 1987, s. 48-58; P. Konieczny, dz. cyt.; Studying Skywalkers, dz. cyt.

Gwiezdne wojny: Część I - Mroczne widmo, George Lucas, USA 1999; Juliwitte, dz. cyt.

Gwiezdne wojny: Część IV - Nowa nadzieja, George Lucas, USA 1977; Gwiezdne wojny: Część V-Imperium kontratakuje, I. Kershner, USA 1980; P. Konieczny, dz. cyt. 
- $\quad$ O odseparowaniu Anakina od matki wspominałam. Warto nadmienić, że nastąpiło ono, gdy chłopiec miał dziewięć lat ${ }^{10}$. Analogicznie rola, którą Qui-Gon Jinn, a następnie Obi-Wan Kenobi odegrali w życiu młodego Anakina, pozwoliła utożsamić tych bohaterów z arturiańskim magiem ${ }^{11}$. Z kolei przeszłości Rey nie znamy. Wiemy jedynie, że dorastała samotnie na Jakku, a jej pochodzenie zostało przez twórców owiane mgłą tajemnicy ${ }^{12}$.

- Ujawnienie predyspozycji: wspomniane wysokie stężenie midichlorianów stawiało młodego Anakina w szeregu bohaterów, którzy zgodnie z przepowiednią mieli przywrócić równowagę Mocy ${ }^{13}$. Młody Skywalker zawiódł finalnie w przeciwieństwie do króla Artura, ponieważ nie potrafił lub nie chciał poskromić negatywnych emocji. Podobnie samo ujawnienie predyspozycji nie było jednorazowym aktem jak słynne wyciągnięcie miecza z kamienia. W przypadku Anakina spektrum drzemiącej w nim Mocy poznawano stopniowo ${ }^{14}$. Dla odmiany Rey niczym król Artur przypadkowo przekonuje się o własnych możliwościach. W jej przypadku owym mitycznym wydobyciem miecza z kamienia była skuteczna i niepoparta żadnym szkoleniem umiejętność opierania się Mocy Kylo Rena ${ }^{15}$.

- Misja: zarówno Luke’owi, Anakinowi, jak i być może Rey zostaje narzucona rola wybrańców. Ten pierwszy miał pokonać Dartha Vadera oraz imperatora ${ }^{16}$. Jak wspomniano, jego ojciec miał przywrócić Mocy równowagę 1 . Tym samym cel obojga był zbieżny z nadrzędnym zadaniem tytułowego bohatera cyklu arturiańskiego. W tych trzech przypadkach chodziło o zapewnienie pokoju - czy to Brytom, czy to w uniwersum galaktycznym ${ }^{18}$. Szczegóóów misji Rey jeszcze nie znamy. W każdym razie drzemiąca w niej Moc oraz szkolenie pod kierunkiem Luke’a być może predestynują tę postać do stawienia czoła Ciemnej Stronie Mocy ${ }^{19}$.

Powyższe i, co istotne, wyrywkowe zestawienie pozornie wykazuje korelację kilku motywów z arturiańskimi opowieściami oraz losami ich głównego bohatera. Niemniej na przykład okoliczności poczęcia Anakina być może w większym stopniu

\footnotetext{
10 Mroczne widmo, dz. cyt.

11 Star Wars/Arthurian Legend, dz. cyt.; inni utożsamiali Obi-Wana Kenobiego z Panią Jeziora: Studying Skywalkers, dz. cyt.

12 Gwiezdne wojny: Przebudzenie Mocy, J.J. Abrams, USA 2015.

13 Mroczne widmo, dz. cyt.

14 Gwiezdne wojny: Część III - Zemsta Sithów, G. Lucas, USA 2005; Star Wars/Arthurian Legend, dz. cyt.; Juliwitte, dz. cyt.

Przebudzenie Mocy, dz. cyt.

Nowa nadzieja, dz. cyt.; Star Wars/Arthurian Legend, dz. cyt.; Juliwitte, dz. cyt.

Mroczne widmo, dz. cyt.

Juliwitte, dz. cyt.

Przebudzenie Mocy, dz. cyt.
} 
nawiązywały do ewangelicznej narracji o zwiastowaniu i wcieleniu Syna Bożego (Łk 1,26-38). Mowa tu o braku ziemskiego ojca oraz o nadprzyrodzonej sile czy mocy, która powołała do życia zarówno młodego Skywalkera, jak i Chrystusa. Ponadto wspomniane ujawnienie predyspozycji Anakina i Rey, które tak ochoczo zestawiono z wydobyciem legendarnego artefaktu, nie było niczym innym jak perypetia, czyli „nagłą zmianą. Jak podano w Stowniku terminów literackich, perypetia jako pojęcie znamienne między innymi dla tragedii greckiej, z jednej strony, odpowiadała za gwałtowny zwrot akcji w narracjach, $\mathrm{z}$ drugiej natomiast, była tożsama z przełomem w życiu bohaterów literackich, z wydarzeniem, które odmieniało w sposób radykalny ich $\operatorname{los}^{20}$. Dodajmy, że motyw przemiany bohatera pod wpływem pewnych okoliczności zauważamy także w Biblii. Mowa tu na przykład o metamorfozie świętego Pawła. Co prawda w jego przypadku miała ona głębszy wymiar niż ten obserwowany w opowieściach arturiańskich i Gwiezdnych wojnach, bo wiązała się z nawróceniem, przemianą duchową. Mimo to w jej efekcie Paweł został wybrany do służby Chrystusowi i obrony chrześcijan, czyli w pewnym sensie obarczony misją (Dz 9,3-7; Dz 22,9; Dz 26,13-18). Zatem należałoby raczej uznać, że motyw metamorfozy i związanej z nią misji były toposami funkcjonującymi w szeroko rozumianej spuściźnie literackiej i to z niej czerpali zarówno autorzy narracji arturiańskich, jak i twórcy Gwiezdnych wojen.

Równie ostrożnie powinniśmy podejść do recepcji motywu miecza ${ }^{21}$. Znawcy zagadnienia akcentowali, że u podstaw koncepcji miecza świetlnego legły opowieści o Excaliburze. Emilio Ortega-Arjonilla oraz Ana Belén Martínez-López wskazali na swoistą integrację tych artefaktów z posiadaczami, która została wyeksponowana także $w$ innych narracjach nawiązujących do legend arturiańskich, jak przykładowo w powieściach J.R.R. Tolkiena. Kolejnym wyróżnikiem było postrzeganie mieczy jako swoistych identyfikatorów poszczególnych formacji lub bohaterów literackich. I tak Excalibur legitymizował pochodzenie Artura jako spadkobiercy spuścizny Uthera, również Andúril wskazywał na dziedzictwo Aragorna. Nie inaczej było w przypadku miecza świetlnego, który pozostawał w ścisłym związku z konkretnym Jedi. Akt zespolenia inicjowano na etapie wytwarzania broni. Ten skomplikowany proces rozpoczynało odnalezienie kryształu, czyli najistotniejszej części miecza. Następnie przyszły posiadacz napełniał go stopniowo Mocą podczas medytacji. Na koniec przygotowany tym sposobem kryształ wraz z pozostałymi elementami broni ulegał ostatecznej obróbce ${ }^{22}$.

20 Zob. M. Głowiński i in., Stownik terminów literackich, Wrocław 1998, s. 382.

Na temat inspiracji twórców różnymi taktykami walki stosowanymi na różnych etapach dziejów oraz w rozmaitych kulturach: N. Jamilla, dz. cyt., passim.

Luke Skywalker skonstruował własny miecz, jednak użyty kryształ nie był naturalny, tylko syntetyczny, zatem cały proces przebiegał w tym wypadku odmiennie: S. Perry, Gwiezdne wojny. Cienie imperium, tłum. J. Kotarski, Warszawa 1996, s. 30-32, 45-46, 97-98. 
Zatem wspomniane zjawisko integracji miecza świetlnego z posiadaczem pozwalało postrzegać ten artefakt jako atrybut przypisany konkretnemu Jedi ${ }^{23}$.

Reasumując: integracja oraz identyfikacja to dwa hasła, które zdaniem wspomnianych autorów definiowały miecz świetlny jako pokłosie arturiańskiego Excalibura. Czy słusznie? Sądzę, że to spojrzenie jest zbyt ograniczone. W moim przekonaniu raczej cała spuścizna literacka i kulturowa wpłynęła na wykreowany obraz. Wspomniana identyfikacja oraz w mniejszym stopniu integracja nie były cechami immanentnymi jedynie miecza z kamienia. Sam miecz był przecież atrybutem bellatores, czyli drugiej grupy współtworzącej wraz z oratores oraz laboratores średniowieczne społeczeństwo. Jedynie osoby parające się rzemiosłem wojennym były uprawnione do jego noszenia. Ponadto miecz posiadał określoną symbolikę: łączono go z prawdą, sprawiedliwością, gniewem Bożym; uważano, że był nośnikiem magii; odnoszono się do niego z czcią, ponieważ nie raz przy jego pomocy walczono o szczytne cele ${ }^{24}$. Ten ostatni aspekt dostrzegamy nie tyle w cyklu arturiańskim, ile przykładowo w literaturze parenetycznej (chociażby w Pieśni o Rolandzie). Wykreowano w niej obraz idealnego rycerza, który kierował się dumą oraz honorem. Okazywał on nadzwyczajny szacunek własnej broni, która nie tylko zaświadczała o jego przynależności do stanu rycerskiego, ale także służyła wojownikowi pomocą w obronie wartości i ideałów. Miecz mógł posiadać własne imię, jak przykładowo Durendal (miecz Rolanda) czy Balmung (miecz Zygfryda); ponadto chroniono go przed przejęciem przez wrogów (postawa Rolanda), co pozwala postrzegać ten atrybut jako personifikację żyjącej jednostki ${ }^{25}$. To skrótowe zestawienie pokazuje, że być może nie tyle miecz arturiański inspirował twórców koncepcji miecza świetlnego, ile znowuż idee obu artefaktów czerpały z tego samego źródła, którym był szeroko rozumiany dorobek kulturowy oraz literacki.

\section{MlŁOŚĆ DWORSKA (DWORNA)}

Ci sami autorzy wskazali na recepcję literackiego motywu miłości dworskiej w niektórych częściach Gwiezdnych wojen. E. Ortega-Arjonilla oraz A. Belén Martínez-López podali, że cechami identyfikującymi średniowieczny motyw miłości dworskiej były: idea trójkąta miłosnego oraz przeszkody dzielące kochanków. Oba wyróżniki dostrzeżono w obrazach miłości Hana Solo i księżniczki Lei oraz

E. Ortega-Arjonilla, A. Belén Martínez-López, dz. cyt., s. 224-226; por. Star Wars/Arthurian Legend, dz. cyt.; P. Konieczny, dz. cyt.; Studying Skywalkers, dz. cyt.

24 Zob. J.E. Cirlot, Stownik symboli, przeł. I. Kania, Kraków 2000, s. 253-255; H. Biedermann, Leksykon symboli, przeł. J. Rubinowicz, Warszawa 2001, s. 216-217.

25 Zob. Pieśń o Rolandzie, tłum. T. Boy-Żeleński, wstęp Z. Czerny, Warszawa 1981, s. 69-72, 76, 79, 82, 84-85, 94-95, 99-101. 
Anakina i królowej Naboo Padmé. Dodajmy, że owe akcentowane w literaturze średniowiecznej przeszkody były najczęściej tożsame z zaangażowaniem pary we wspomniany trójkąt miłosny. Zarówno Lancelot i Ginewra, jak i Tristan z Izoldą doświadczyli zakazanej miłości ze względu na postacie króla Artura, a także króla Marka. Dla odmiany w uniwersum Gwiezdnych wojen czynnik osobowy został zastąpiony przez: 1) społeczne nierówności oraz 2) powinności wynikające z pełnionej funkcji. Te pierwsze odnajdujemy w kreacji uczucia księżniczki Lei oraz przemytnika Hana Solo, natomiast drugie - w obrazie miłości młodego Skywalkera, który miał poświęcić się szkoleniu, oraz Padmé, która najpierw piastowała godność królowej Naboo, a następnie pełniła funkcję senatora ${ }^{26}$.

O ile pogląd na temat recepcji motywu miłości dworskiej w przypadku Anakina oraz Padmé wydaje się uzasadniony, o tyle uczucie oraz koleje losu Lei i Hana Solo zdają się niekiedy odbiegać od tego modelu ${ }^{27}$. Najpierw jednak zdefiniujmy precyzyjniej samo pojęcie miłości dworskiej. Średniowieczna koncepcja miłości (fin amor), którą dopiero w XIX stuleciu zaczęto określać mianem dworskiej (dwornej), odnosiła się do związku potajemnego, którego ujawnienie było niemożliwe z racji istotnych przeciwności. Jak wspominałam, niekiedy te przeszkody definiowano jako zaangażowanie pary w trójkąt miłosny. Ponadto sekretny charakter miłości wprowadzał kochanków w skrajne stany emocjonalne, jak bezgraniczna tęsknota, napięcie, przygnębienie czy euforia, co stanowiło konsekwencję naprzemiennego doświadczania rozłąki oraz wspólnych momentów ${ }^{28}$. Co interesujące, miłość dworska nawiązywała do idei związku kreowanego w opozycji do małżeństwa. Zdaniem Waldemara Kuligowskiego: „Zachowane do dzisiaj Dzieje Tristana i Izoldy nie przepuszczają żadnej okazji, żeby poniżyć postać męża, żeby zohydzić instytucję związku małżeńskiego. Pochwalne peany dotyczą w tym wypadku wyłącznie tych, którzy kochają poza małżeństwem, a nawet po prostu wbrew niemu" ${ }^{29}$. Takie podejście stanowiło konsekwencję małżeństwa postrzeganego głównie jako zabieg polityczny oraz ekonomiczny, które z uczuciem oraz samodzielnym wyborem przyszłych małżonków miało niewiele wspólnego ${ }^{30}$. Wzorzec miłości dworskiej wykreowano w średniowiecznej literaturze, niemniej odnotowano w historii pary, które doświad-

E. Ortega-Arjonilla, A. Belén Martínez-López, dz. cyt., s. 227-229; por. W. Williams, dz. cyt.; Juliwitte, dz. cyt.; ten motyw dostrzeżono w filmach: Nowa nadzieja, dz. cyt.; Imperium kontratakuje, dz. cyt.; Gwiezdne wojny: Część VI - Powrót Jedi, R. Marquand, USA 1983; Gwiezdne wojny: Część II - Atak klonów, G. Lucas, USA 2002; Zemsta Sithów, dz. cyt.

Na temat Padmé i Anakina: W. Williams, dz. cyt.; Juliwitte, dz. cyt.

W. Kuligowski, Miłość na Zachodzie. Historia antropologiczna, Poznań 2004, s. 127-131.

Tamże, s. 127.

Tamże; D. Ackerman, Historia naturalna mitości, tłum. D. Gostyńska, Warszawa 1997, s. 80. 
czyły takiego stanu. Co istotne, zarówno w przypadku Tristana i Izoldy, jak i Abelarda oraz Heloizy chodziło o uczucie pozamałżeńskie 31 .

Model miłości dworskiej był ściśle powiązany ze statusem kobiety. Warto nadmienić, że w wiekach średnich wypchnięto kobietę na margines. Zdaniem Marii Boguckiej u podstaw tegoż leżał system feudalny, w ramach którego stosunki między możnymi regulowały zasady związane z prowadzeniem wojen. Oparcie wielu struktur na kwestiach militarnych automatycznie wyeliminowało kobietę jako istotę słabą pod względem fizycznym. W związku z tym kobiety były upośledzone w sferze ekonomicznej oraz prawnej. Towarzyszyły temu poglądy rozpowszechniane przez Kościół na temat roli Ewy w upadku pierwszego mężczyzny, co wpłynęło na percepcję całej żeńskiej populacji. Kobietę traktowano jako narzędzie szatana i osobę gorszą nie tyle pod względem fizycznym, ile duchowym, moralnym ${ }^{32}$. Takiemu postrzeganiu kobiety sprzeciwiali się piewcy miłości dworskiej. Trubadurzy wielbili kobiety oraz stawiali je na piedestale ${ }^{33}$. Z ideą minne (miłości do kobiety) związane było kreślenie schematu, zgodnie z którym kobieta posiadała wyższy status od adorującego ją mężczyzny. Z kolei bohaterskie czyny rycerza miały jeden cel: wykazanie własnej wartości, która wzbudzała podziw w oczach wybranki ${ }^{34}$.

Uczucie, którego doświadczyli Padmé i Anakin, wykreowano zgodnie z koncepcją średniowiecznej fin amor ${ }^{35}$. Ten pogląd wydaje się słuszny, ponieważ łączące ich relacje oraz dzieje tego związku wpisywały się w nakreślone standardy. Zdaniem Wesleya Williamsa schemat miłości królowej Naboo oraz Jedi prezentował się następująco.

31 M. Bogucka, Gorsza płeć. Kobieta w dziejach Europy od antyku po wiek XXI, Warszawa 2005, s. 83-87; por. W. Kuligowski, dz. cyt., s. 141-145.

32 M. Bogucka, dz. cyt., s. 87-88; por. W. Kuligowski, dz. cyt., s. 113-116.

W. Kuligowski, dz. cyt., s. 119-126.

Tamże, s. 121-127, 130-131.

W. Williams, dz. cyt.; Juliwitte, dz. cyt. 


\begin{tabular}{|c|c|}
\hline Schemat miłości dworskiej: & Padmé i Anakin: \\
\hline Młody rycerz i starsza od niego dama & Padmé jest starsza od Anakina \\
\hline Wysoki status kobiety & Padmé jako królowa Naboo, a następnie \\
senator
\end{tabular}

W. Wiliams sformułował ten pogląd na podstawie dwóch ekranizacji: Ataku klonów oraz Zemsty Sithów. To niebudzące kontrowersji zestawienie pokazuje, że podczas kreacji relacji łączących parę dopełniono wszelkich warunków. Starsza od Anakina Padmé budziła respekt przez wzgląd na piastowane godności. Jej opór przed zaangażowaniem w związek stanowił konsekwencję szerszej perspektywy, u której podstaw leżały wiek, status społeczny oraz doświadczenie i mądrość jako pochodne tych pierwszych. Zdaniem W. Williamsa postać młodego Jedi wykreowano również zgodnie z koncepcją średniowiecznej miłości dworskiej ${ }^{36}$. Jego zapalczywość, zaangażowanie oraz miłosne zabiegi stanowiły recepcję postawy młodego rycerza adorującego wybrankę $^{37}$. Co więcej, autor odnotował, że losy wspomnianej pary stanowiły idealne odwzorowanie etapów miłości kochanków, które znamy z literatury średniowiecznej.

36 W. Williams, dz. cyt.; por. Juliwitte, dz. cyt.

37 Atak klonów, dz. cyt.; por. Zemsta Sithów, dz. cyt. 


\begin{tabular}{|c|c|}
\hline Etapy dworskiej miłości: & Anakin i Padmé: \\
\hline Oczarowanie & $\begin{array}{l}\text { Scena, w której Anakin i Padmé są sami po raz pierwszy; } \\
\text { Anakin posyła Padmé znaczące spojrzenia; odpowiedź Padmé: } \\
\text { „Nie patrz tak na mnie. Przez to czuję się niekomfortowo” }\end{array}$ \\
\hline Wielbienie z oddali & $\begin{array}{c}\text { Anakin mówi do Jar Jar Binksa: „Odkąd się rozstaliśmy, } \\
\text { myślałem o niej codziennie” }\end{array}$ \\
\hline Wyznanie & Anakin wielokrotnie wspominał Padmé o uczuciu \\
\hline Zabieganie o względy & $\begin{array}{l}\text { Anakin zamierza zidentyfikować zleceniodawców zamachu } \\
\text { na Padmé }\end{array}$ \\
\hline $\begin{array}{c}\text { Męki } \\
\text { niespełnionej miłości }\end{array}$ & $\begin{array}{c}\text { „Od chwili, gdy cię poznałem... przed tyloma laty... nie było } \\
\text { dnia, bym o tobie nie pomyślał. A teraz, gdy znów jestem przy } \\
\text { tobie... cierpię męki. Im bardziej się do ciebie zbliżam, tym } \\
\text { bardziej cierpię. Na myśl, że nie będę z Tobą... duszę się. } \\
\text { Wspominam pocałunek, którym nie powinnaś mnie obdarzyć. } \\
\text { Serce mi wali w nadziei, że ten pocałunek nie zamieni się } \\
\text { w bliznę. Wdarłaś się w moją duszę. Dręczysz mnie. Co robić?”. } \\
\text { Te słowa to kwintesencja uczuć znamiennych dla miłości } \\
\text { dworskiej }\end{array}$ \\
\hline Bohaterskie czyny & $\begin{array}{c}\text { Anakin ocalił Padmé życie; Anakin jako „ochroniarz” Padmé; } \\
\text { bohaterska próba uratowania matki Anakina, w której Padmé } \\
\text { także bierze udział }\end{array}$ \\
\hline Spełnienie & Ślub na Naboo \\
\hline Związek potajemny & $\begin{array}{l}\text { Ukrywanie związku przed otoczeniem oraz tożsamości ojca } \\
\text { dziecka }\end{array}$ \\
\hline Tragiczny finał & $\begin{array}{l}\text { Padmé umiera po porodzie, ponieważ utraciła wolę życia. } \\
\text { Winny był Anakin, ponieważ przeszedł na Ciemną Stronę } \\
\text { Mocy; Darth Vader finalnie „zabił” Anakina }\end{array}$ \\
\hline
\end{tabular}


Usystematyzowane w tabeli 2 spostrzeżenia W. Williamsa korelowały z wykreowanym w literaturze średniowiecznej schematem miłości dworskiej. Dodajmy, że tragiczny finał stanowił w szczególności warunek sine qua non koncepcji fin amor. W ten model idealnie wpisano uczucie bohaterów Ataku klonów i Zemsty Sithów. Przejście Anakina na Ciemną Stronę Mocy było procesem długotrwałym, a u podstaw tegoż leżało między innymi pragnienie ochrony Padmé przed śmiercią. Niemniej jego ostateczna metamorfoza nastąpiła po pojedynku na Mustafar, który został niejako sprowokowany przez samą Padmé. Kiedy Jedi przekonał się, że Padmé towarzyszył Obi-Wan Kenobi, zarzucił jej zdradę, co finalnie doprowadziło do jego okaleczenia w walce oraz konieczności noszenia maski i zbroi podtrzymujących funkcje życiowe ${ }^{38}$. Anakin, przechodząc na Ciemną Stronę Mocy, w pewnym sensie popełnił samobójstwo. Wspominano o tym w Nowej nadziei, a precyzyjniej w scenie, w której Obi-Wan Kenobi mówił do Luke’a: „Vader [... ] zdradził i zabił twojego ojca”. Młody Jedi, stając się Darthem Vaderem, w istocie zdradził własne posłannictwo, ponieważ uznano go za wybrańca, który miał przywrócić Mocy równowagę, zatem sama przemiana oznaczała kres jego egzystencji ${ }^{39}$.

\section{ŚREDNIOWIECZNY OBRAZ PIEKŁA}

Pozbawione jakichkolwiek trudności okazało się zidentyfikowanie średniowiecznych motywów eschatologicznych w uniwersum Gwiezdnych wojen. Niemniej to zagadnienie analogicznie do pozostałych wymagało ostrożnego podejścia, a wnioski mogły budzić kontrowersje. Na wstępie warto zaznaczyć, że średniowieczna literatura oraz ikonografia, w której spotykamy obraz piekła, miały przede wszystkim charakter dydaktyczny. Konieczność nakłonienia zatwardziałych grzeszników do zmiany postępowania narzuciła wizję tortur, których zakres odwoływał się do systemu kar znanego autorowi danego dzieła, a krajobraz piekła przywodził na myśl obszary o skrajnie surowych warunkach geograficznych lub krainy zdominowane przez niszczycielskie żywioły. Ponieważ ogień postrzegano jako „groźny, niszczycielski żywioł, zdolny zniweczyć cały ludzki dobytek [...], mogący być przyczyną dotkliwego bólu, skutecznie oddziaływał na wyobraźnię człowieka”, więc wprowadzono go jako główny motyw piekła ${ }^{40}$.

\footnotetext{
Zemsta Sithów, dz. cyt.; W. Williams, dz. cyt.

Tamże; Nowa nadzieja, dz. cyt.; Imperium kontratakuje, dz. cyt.; Star Wars/Arthurian Legend, dz. cyt.; Juliwitte, dz. cyt.

40 S. Bylina, Wyobrażenie piekła w średniowiecznej Polsce (XIV-XV w.), „Polska Sztuka Ludowa. Konteksty” 1986, t. 40, z. 1-2, s. 98, 99; na temat roli strachu w kazaniach o piekle: G. Minois, Historia piekta, tłum. A. Kędzierzawska, B. Szczepańska, Warszawa 1998, s. 134-138.
} 
Ogień to pożary, a także zwęglone na ich skutek ciała, których widok był częstym udziałem średniowiecznego człowieka. Ten motyw chętnie angażowano w narracjach kaznodziejskich, w tym powstałych na ziemiach polskich. Stanisław Bylina podał przykład pochodzący z narracji Peregryna z Opola, w której opisano przypadek pewnego grzesznika porwanego do piekła, gdzie poddano go torturom. Na koniec pozwolono mu powrócić, aby opowiedział o katuszach. Dodajmy, że ciało tego mężczyzny było częściowo spalone $e^{41}$. Jak wspominał historyk, ogień to również stosy, które głównie poza obszarem polskim grozily za herezję, a w Polsce dodatkowo za podpalenie czy fałszowanie monety. Mimo to wpłynęły one w mniejszym stopniu na kreowany obraz piekieł. W każdym razie ogień był jednym z tych elementów, który z powodu osobistych doświadczeń jednostek budził strach przed karami piekielnymi ${ }^{42}$.

Średniowieczne piekło przedstawiano jako krajobraz nie tylko „skąpany” w ogniu, ale także poprzecinany rzekami lawy. Te wizje rzek ognia charakterystyczne były już dla dzieł autorów antycznych, jak chociażby Platona, który w dialogu Fedon opisał Pyriflegeton: „Nurty jej tu i ówdzie, i na powierzchni ziemi strumieniami lawy buchają ${ }^{3}$. W średniowieczu i czasach nowożytnych dostrzegamy ten motyw zarówno u autorów literackich wizji zaświatów, jak i w malarstwie na przykład Hansa Memlinga czy Hieronima Boscha ${ }^{44}$. Z kolei te wizje przywodzily na myśl wulkaniczną planetę Mustafar, znaną chociażby z ostatnich scen Zemsty Sithów. Walka Anakina z Obi-Wan Kenobim rozgrywała się właśnie w scenerii rzek lawy i ognia, a krajobraz był dodatkowo zdominowany przez dym i popiół wydobywający się z wulkanów ${ }^{45}$.

Sceneria Mustafar korespondowała także z motywem grzesznika kuszonego przez diabła, bo kim jak nie grzesznikiem był Anakin zwiedziony przez Palpatine’a do przejścia na Ciemną Stronę Mocy w zamian za ratowanie życia Padmé? Ponadto Ryan Croft zauważyl, że ten motyw wzbogacono o recepcję wątków z Boskiej Komedii

S. Bylina, dz. cyt., s. 98-99; na temat wizji piekła, w których dominował ogień: A. Turner, Historia piekła, thum. J. Jarniewicz, Gdańsk 1996, s. 88.

42 S. Bylina, dz. cyt., s. 98-99.

43 Platon, Fedon [w:] tenże, Dialogi, t. 1, tłum. i wstęp W. Witwicki, Kęty 1999, s. 708; cyt. za J. Sokolski, Staropolskie zaświaty. Obraz piekła, czyśćca i nieba w renesansowej i barokowej literaturze polskiej wobec tradycji średniowiecznej, Wrocław 1994, s. 117-118.

44 Jacek Sokolski zestawił średniowieczne literackie opisy zaświatów (w tym piekieł) oraz omówił ich recepcję w wiekach późniejszych: tenże, dz. cyt., s. 11-237; piekło w obrazach, przykładowo: Hans Memling, Sąd ostateczny, ok. 1467-1471, Muzeum Narodowe w Gdańsku [w: ] Flemish \& Dutch Painting, ed. by B. Silvia, Bagno a Ripoli-Köln 2010, s. 66; Hieronim Bosch, Siedem grzechów głównych, ok. 1475-1480, Museo Nacional del Prado, Madrid [w: ] Flemish \& Dutch Painting, dz. cyt., s. 114; tenże, Wóz z sianem, ok. 1500-1502, Museo Nacional del Prado, Madrid [w: Flemish \& Dutch Painting, dz. cyt., s. 116; tenże, Ogród ziemskich rozkoszy, ok. 1503-1504, Museo Nacional del Prado, Madrid [w: ] Flemish \& Dutch Painting, dz. cyt., s. 123; por. A. Turner, dz. cyt., s. 78-97, 126-129; G. Minois, dz. cyt., s. 125-126.

45 Zemsta Sithów, dz. cyt. 
Dantego ${ }^{46}$. Wizja Dantego zakładała istnienie dziewięciu kręgów piekielnych, a samo piekło miało kształt odwróconego stożka. Ostatni krąg podzielony został na cztery strefy i przeznaczony był dla zdrajców ${ }^{47}$. I ponownie możemy zadać pytanie: kim był Anakin jak nie zdrajcą? Zdradził idee Jedi i Jasną Stronę Mocy, porzucając ją na rzecz Ciemnej, ponadto zdradził samych Jedi, dowodząc legionem, który zaatakował świątynię, a w końcu zdradził Senat i Republikę, umożliwiając Kanclerzowi przeprowadzenie zamachu stanu ${ }^{48}$. Pojedynek Anakina z Obi-Wanem w scenerii Mustafar był symbolicznym dziewiątym kręgiem piekła: Skywalker niczym średniowieczny grzesznik został „poddany torturom”, wskutek tego okaleczony (utrata kończyn) oraz rozlegle poparzony.

\section{JEDI JAKO TEMPLARIUSZE}

Osoby eksplorujące problematykę recepcji motywów średniowiecznych w uniwersum galaktycznym akcentowały liczne korelacje pomiędzy Jedi a templariuszami oraz samurajami z feudalnej Japonii, czym zajmiemy się później ${ }^{49}$. W obu przypadkach wspomniane analogie należałoby usystematyzować. Templariuszy łączyły z Jedi niejako „wspólne” dzieje, a ponadto dostrzeżono zbieżności na plaszczyźnie organizacyjnej ${ }^{50}$. W tej pierwszej grupie akcentowano recepcję motywu kasaty templariuszy. Chodziło o zamach stanu, którego autorem był Kanclerz Palpatine, oraz o próbę eksterminacji wszystkich Jedi ${ }^{5}$. Nie inaczej potoczyly się losy templariuszy. Zakon powstał na terenie Ziemi Świętej po pierwszej krucjacie, a po upadku Akki w 1291 roku przeniesiono jego główną siedzibę najpierw na Cypr, a następnie do Francji. W 1307 roku na zlecenie Filipa IV Pięknego aresztowano templariuszy przebywających na terenie królestwa, a w 1312 roku po kilkuletnim procesie Klemens V pod naciskiem króla wydał bullę, na mocy której rozwiązano zakon ${ }^{52}$. Co więcej, zarówno w odniesieniu do Jedi, jak

46 Ryan Croft wielokrotnie akcentował taką zależność. Dodajmy, że badacz od lat analizuje korelacje pomiędzy literaturą średniowieczną oraz światem filmu. Tym zagadnieniom poświęcone zostały przede wszystkim zajęcia, które R. Croft prowadzi na Uniwersytecie Wyoming, o czym wspominał w wywiadzie udzielonym Mary Jung: R. Croft, Medieval Literature and Star Wars, rozm. przepr. M. Jung [online], 2014 [dostęp: 4 maja 2017]. Dostępny w World Wide Web: https://www.youtube.com/watch?v=8PDYdaRa_a4; por. P. Konieczny, dz. cyt.

47 Dante Alighieri, Boska komedia (wybór), tłum. E. Porębowicz, wstęp K. Morawski, Wrocław 1977, s. 143-162; na temat piekła u Dantego: A. Turner, dz. cyt., s. 111-119; G. Minois, dz. cyt., s. 127-131.

48 Zemsta Sithów, dz. cyt.

49 Terrance MacMullan wskazał także na mnichów z klasztoru Shaolin, którzy obok templariuszy i samurajów zainspirowali twórców: tenże, dz. cyt.; cyt. za P. Konieczny, dz. cyt.

50 Tamże; D. Pahman, dz. cyt.

51 Zemsta Sithów, dz. cyt.

52 Na temat historii oraz organizacji templariuszy powstało wiele prac. Martin Bauer usystematyzował mniej lub bardziej oczywiste fakty: tenże, Templariusze. Mity i rzeczywistość, tłum. M. Słabicka, Wrocław 2003, passim; o kasacie templariuszy, oskarżeniach, procesie oraz postaci ostatniego wielkiego mistrza: A. Demurger, Jakub de Molay. Zmierzch templariuszy, tłum. M. Satora, Toruń 2012. 
i templariuszy możemy mówić o zdradzie, która leżała u podstaw kasaty obu formacji. Jedi doświadczyli jej ze strony wspomnianego Palpatine’a, który zarządził likwidację zakonu jako Kanclerz, czyli osoba nadrzędna w Republice Galaktycznej - tej Republice, której Jedi strzegli. Ponadto w ten spisek został zaangażowany Anakin, który dowodził legionem atakującym świątynię ${ }^{53}$. Przeciwko templariuszom zaś najpierw wystąpił wspomniany Filip IV jako gospodarz państwa, na terenie którego posiadali dobra, a następnie papież jako ich formalny zwierzchnik. Zatem w obu przypadkach wspomniana zdrada miała podwójny charakter.

Dylan Pahman sformułował poglądy na temat mistyfikacji oraz sfery legend jako kolejnych wspólnych płaszczyzn. Przeciwko Jedi wysunięto nieprawdziwe zarzuty zdrady Republiki, Senatu oraz próby zamachu na życie Kanclerza, natomiast templariuszy fałszywie oskarżono o zdradę chrześcijaństwa i moralności, a precyzyjniej zarzucono im kult Bafometa, bluźniercze praktyki podczas inicjacji i sodomię. Losy templariuszy stały się kanwą wielu legend, zgodnie z którymi rycerze mieli odnaleźć i chronić Świętego Graala; definiowano ich także jako tajne bractwo stojące na straży wielkiej tajemnicy lub równie sekretnego skarbu ${ }^{54}$. Dla odmiany Jedi po likwidacji utożsamiano z mitem, na poły legendarnym tworem, w którego przeszłe dzieje powątpiewano ${ }^{55}$.

W tekstach podkreślano także analogie w sferze organizacyjnej oraz w ramach nadrzędnego celu obu formacji. Zarówno Jedi, jak i templariuszy powołano do ochrony społeczności w ramach określonych organizmów politycznych. Jedi utożsamiano ze strażnikami pokoju i sprawiedliwości w Republice Galaktycznej. Zresztą sami rycerze definiowali się w ten sposób. W jednej z pierwszych scen Zemsty Sithów Mace Windu mówił: „jesteśmy strażnikami pokoju, nie żołnierzami” ${ }^{\text {”6 }}$. Nie inaczej sformułowano zadanie, do którego wypełnienia powołano templariuszy. Pomiędzy 1118 a 1120 rokiem Hugo de Payens wraz z nielicznymi towarzyszami zobowiązał się do przestrzegania ślubów zakonnych oraz obrony pielgrzymów oraz samej Ziemi Świętej przed muzułmanami ${ }^{57}$.

Kolejne analogie dotyczyły: centralnej siedziby oraz zaleceń odnoszących się do sfery życia prywatnego. Każdy z zakonów, czy to Jedi, czy to Zakon Ubogich Rycerzy Chrystusa i Świątyni Salomona, posiadał centralny punkt na mapie własnego uniwersum. Dodajmy, że świątynia na Coruscant odgrywała nieco inną rolę w życiu Jedi niż Świątynia Salomona. Ta pierwsza funkcjonowała jako realne zaplecze dla każdego rycerza (kwatery, siedziba Najwyższej Rady, miejsce szkoleniowe, archiwum), nato-

\footnotetext{
M. Bauer, dz. cyt., passim; P. Konieczny, dz. cyt.; D. Pahman, dz. cyt. Mit templariuszy zweryfikował Martin Bauer: dz. cyt., s. 139-177. Przebudzenie mocy, dz. cyt.; D. Pahman, dz. cyt.

Zemsta Sithów, dz. cyt.

Te analogie akcentowali: P. Konieczny, dz. cyt.; D. Pahman, dz. cyt.
} 
miast wspomniane Templum, które odcisnęło piętno w nazwie rycerzy w habitach, odnosiło się głównie do sfery ideowej ${ }^{58}$.

Kontrowersyjne wydaje się usilne poszukiwanie analogii w ramach struktur zwierzchnich obu zakonów ${ }^{59}$. Najwyższa Rada Jedi składała się z dwunastu Mistrzów, którzy nie tylko decydowali o losach formacji, ale także służyli wsparciem władzom Republiki. W tej hierarchii na próżno by szukać funkcji wielkiego mistrza, choć niektórzy w takiej nieformalnej roli widzieli Yodę. Templariusze byli zarządzani przez wspomnianego mistrza, którego wybierano. Wielki mistrz kierował zakonem w sposób nie do końca samowładny, lecz przy wsparciu kapituły składającej się między innymi z seneszala, marszałka oraz komandorów ${ }^{60}$. Zatem, z jednej strony, mamy do czynienia z kompletnie odmienną strukturą jednostki zarządzającej, z drugiej natomiast, z niepodobnymi regułami odnośnie do sprawowania władzy.

Obie formacje określano mianem zakonu. Jak wiadomo, rycerze w habitach otrzymali określone ramy organizacyjne głównie dzięki zaangażowaniu Bernarda z Clairvaux oraz pod wpływem reguły benedyktyńskiej. Podobnie Jedi odwoływali się do zasad życia zakonnego jako organizacja o bardzo długim rodowodzie, której członkowie byli zunifikowani przez określoną obserwancję oraz narzucone funkcje ${ }^{61}$. Dopełnieniem powyższego obrazu było zalecenie, aby zarówno Jedi, jak i templariusze nie angażowali się emocjonalnie ${ }^{62}$. Przykładowo w Ataku klonów Anakin tłumaczył Padmé, że „zakazane jest przywiązanie. Zakazane jest posiadanie”, po czym przewrotnie dodał: „Współczucie, czyli bezwarunkowa miłość, to wyznacznik życia Jedi. Można powiedzieć, że zachęca się nas do miłości”. W Zemście Sithów Mistrz Yoda przedstawił tę kwestię w bardziej racjonalnym świetle: „Przywiązanie prowadzi do zazdrości. Ona chciwości ciemną stroną jest" ${ }^{\circ 3}$. Zatem w szczególności przestrzegano nie przed formalnym związkiem, lecz stanem emocjonalnym, który mógł okazać się katalizatorem porzucenia Jasnej Strony Mocy. Nieco odmiennie ograniczono prywatną sferę życia templariuszy, jakkolwiek nadrzędny skutek wspomnianych norm był taki sam. Templariusze jako rycerze w habitach składali podobnie jak mnisi śluby, w tym ślub czystości. Jak zapisano w regule: „Czystość jest pewnością serca i zdrowiem ciała. Bowiem jeśli jakiś brat nie złoży ślubu czystości, nie będzie mógł osiągnąć wiecznego

\footnotetext{
58 Tamże.

Tamże.

60 M. Bauer, dz. cyt., s. 42-45.

61 Por. P. Konieczny, dz. cyt.; D. Pahman, dz. cyt.; rycerzy Jedi (przykładowo Obi-Wana Kenobiego) zestawiano także ze średniowiecznymi eremitami: T. Henthorne, dz. cyt., s. 79.

Tamże.

Atak klonów, dz. cyt.; Zemsta Sithów, dz. cyt.
} 
odpoczynku ani ujrzeć Boga” ${ }^{\text {4 }}$. Co interesujące, pierwsza część zacytowanego zdania reguły była bliska słowom Mistrza Yody. Wspomniany przez niego brak przywiązania miał ustrzec Jedi przed emocjami, które de facto burzyły wzmiankowaną w regule templariuszy pewność serca.

\section{JEDI JAKO SAMURAJE}

Fascynacja twórcy Gwiezdnych wojen buddyzmem oraz filmami Akiry Kurosawy miała sprowokować przeniesienie idei, którym hołdowali samuraje, do świata galaktycznego ${ }^{65}$. W nielicznych tekstach położono akcent przede wszystkim na recepcję przykładowych zasad: mushin, samodoskonalenia japońskich wojowników, postulatu konieczności eliminacji lęku przed śmiercią, a poza tym obszarem wskazano na symbolikę miecza, która obok arturiańskiego artefaktu leżała u podstaw koncepcji miecza świetlnego, oraz inspirację strojami z okresu feudalnego (hełm Vadera inspirowany samurajskim kabuto $)^{66}$. Na wstępie dodajmy, że zarówno samuraje, jak i Jedi przestrzegali określonego kanonu norm. Oba, czyli „droga wojownika” (bushidō) oraz reguły Jedi, porządkowały obszary funkcjonowania tych grup i w obu akcent położono między innymi na doskonałość, samokontrolę, harmonię, sprawiedliwość, prawdę ${ }^{67}$.

Autorzy przeróżnych przyczynków akcentowali mushin jako kardynalną zasadę, która łączyła obie grupy ${ }^{58}$. Ponownie należałoby zadać pytanie: czy słusznie? Otóż mushin, które tłumaczymy jako „nieświadomość”, „beznamiętnie”, „, bez serca”, odnosiło się do stanu, który samuraj winien osiągnąć podczas walki. Zasada mushin, a niekiedy mushin no shin (umysł pozbawiony myśli), oznaczała stan maksymalnej koncentracji, w którym nie tylko zapominano o otaczającym świecie, ale także odcinano się od własnej świadomości, emocji, a osiągano go przez praktyki medytacyjne ${ }^{69}$. Jeżeli za materiał porównawczy uznamy wyłącznie ekranizacje, to proponowane zestawienie może budzić kontrowersje. Wprawdzie w Nowej nadziei oraz Imperium kontratakuje zalecano młodemu Skywalkerowi, aby wyparł posiadaną wiedzę i działał w oparciu

64 Templariusze. Reguła, tłum. J. Lickiewicz, E. Zabrotowicz [online], 1998-2017 [dostęp: 4 maja 2017]. Dostępny w World Wide Web: www.templariusze.org/index.php?lang=pl\&grupa=22\&kategoria=64.

N. Jamilla, dz. cyt., s. 22.

66 Tamże, passim; T. MacMullan, dz. cyt.; P. Konieczny, dz. cyt.; J. Man, dz. cyt.; A.K. Puchalska, Bushidō. Ethos samurajów od opowieści wojennych do wojny na Pacyfiku, Bydgoszcz 2016, s. 319, 345.

67 A.K. Puchalska, dz. cyt.; na temat bushidō przykładowo: A. Śpiewakowski, Samuraje, tłum. K. Okazaki, Warszawa 1989, s. 14-25; M. Wiatrak, Ideologia kultu samurajskiego miecza. Zarys obrazu w kulturze i spoteczeństwie dawnej Japonii, Oświęcim 2013, s. 109-112; A.K. Puchalska, dz. cyt., passim.

68 T. MacMullan, dz. cyt.; por. P. Konieczny, dz. cyt.

69 A. Śpiewakowski, dz. cyt., s. 48-49, 65-67; na temat mushin (przykładowo): S. Shaw, Samurai Zen, Boston 1999, s. 137. 
o instynkt, poza świadomością, ale jednocześnie żądano od niego ufania własnym emocjom $^{70}$. Zdaje się, że te rady kolidowały z samurajskim „beznamiętnie” i „bez serca". Dla odmiany, jeśli przyjrzeć się mantrze, czyli pięciowersowemu tekstowi, który łączono z filozofią Jedi, a który funkcjonował poza ekranizacjami, to dostrzec można zbieżność zwłaszcza na podstawie pierwszego wersu tego tekstu. „Nie ma emocji, jest spokój” - to hasło niewątpliwie odnosiło się do idei mushin. Zarówno zasada mushin, jak i wzmiankowane hasło były pomocne podczas prób opanowania strachu przed śmiercią. Z kolei do tego postulatu nawiązano w piątym wersie mantry: „Nie ma śmierci, jest Moc”1.

Nieliczni zestawili wspomniany pięciowersowy tekst Jedi z Księga pięciu kręgów spisaną przez żyjącego na przełomie XVI i XVII wieku japońskiego wojownika Musashiego Miyamoto. Akcentowano dwie analogie: strukturalną oraz dotyczącą założeńt ${ }^{72}$. Co do pierwszej: takie zestawienie może budzić sprzeciw, ponieważ wzmiankowane dzieło nie było jedynym pięcioczęściowym tekstem funkcjonującym w ramach szeroko rozumianej tradycji literackiej, kulturowej czy religijnej. Analogicznie zasady, które wyłożono w Księdze pięciu kręgów, były niczym innym jak opisem taktyki i strategii oraz reguł „drogi wojownika”. Dodajmy, że Musashi Miyamoto wzbogacił refleksję na temat zasad o indywidualne spostrzeżenia ${ }^{73}$. Jeżeli uznamy spisane w tej księdze normy, nieobce innym samurajom, za wystarczającą podstawę do dalszych dociekań, to tym samym odnajdziemy zbieżności: między innymi wspomniana konieczność opanowania strachu przed śmiercią, poczucie obowiązku ${ }^{74}$ czy potrzeba ustawicznego samodoskonalenia („doskonalenie serca i pogłębianie mądrości”) ${ }^{75}$. Przyznajmy jednak, że te przykładowe zalecenia miały charakter uniwersalny w odniesieniu do samurajów i dotyczyły zestawu cech, który tworzył obraz idealnego wojownika ${ }^{76}$. Zatem poszukiwanie korelacji pomiędzy systemem wartości i reguł samurajów a Jedi powinno mieć szeroki zakres, nieograniczony do wspomnianej księgi czy zbyt lakonicznej mantry ${ }^{77}$.

Koncepcja miecza świetlnego, z jednej strony, miała się odnosić do arturiańnkiego Excalibura czy symboli miecza w ogóle, z drugiej natomiast, pewne idee wywodzono

\footnotetext{
70 Nowa nadzieja, dz. cyt.; Imperium kontratakuje, dz. cyt.; P. Konieczny, dz. cyt.

71 Mantra była znana z powieści Christie Golden Star Wars. Mroczny uczeń. Powieść została opublikowana w polskim tłumaczeniu (Anny Hikiert-Berezy) w $2016 \mathrm{r}$.

Are the Jedi based upon the Samurai?, dz. cyt.

M. Miyamoto, The Complete Book of Five Rings, wyd. i tłum. K. Tokitsu, Boston-London 2010; sylwetka autora, tamże, s. 1-6; księga ukazała się także w polskim przekładzie: tenże, Księga pięciu kręgów. Gorin no Sho, thum. A. Żuławska-Umeda, Bydgoszcz 2010; por. M. Wiatrak, dz. cyt., s. 112-118.

74 Zalecanego poczucia obowiązku nie należało mylić z absolutnym oddaniem panu feudalnemu, gdyż Musashi Miyamoto był roninem; M. Wiatrak, dz. cyt., s. 115.

75 A.K. Puchalska, dz. cyt., s. 257.

76 Tamże; A. Śpiewakowski, dz. cyt., s. 43-45.

77 O kodeksie Jedi jako pochodnej zasad, którymi kierowali się samuraje: A.K. Puchalska, dz. cyt., s. 345.
} 
z obszaru wierzeń oraz rytuałów związanych z mieczem samurajskim ${ }^{78}$. Wokól japońskiego miecza zrodził się cały system obyczajów, które stanowily pochodną czci, jaką darzono tę broń (na przykład zasady odnoszące się do obnażania klingi czy noszenia broni w domu innego samuraja $)^{79}$. Co istotne, w feudalnej Japonii uznawano, że miecz to dusza wojownika, a rozstanie $\mathrm{z}$ nim było akceptowane jedynie w wypadku śmierci. Co więcej, nieprzestrzeganie tej reguły wieńczyły konsekwencje. W XVII wieku wspominał o tym Ieyasu Tokugawa: „Każdy, kto ma prawo nosić długi miecz, musi pamiętać, że jego miecz powinien być uważany za jego duszę, że może on rozstać się z mieczem jedynie wtedy, kiedy rozstanie się z życiem. Jeżeli zapomni o swoim mieczu, musi zostać ukarany" ${ }^{30}$. Zatem chodziło o ideę integracji z artefaktem czy też jego spersonalizowanie. Dodajmy, że te dwie cechy otrzymały w Gwiezdnych wojnach wymiar adekwatny do uwarunkowań wykreowanej rzeczywistości.

Analiza obrazów z perspektywy widza ( $w$ ramach tego wyrywkowego, siłą rzeczy, tekstu) umożliwiła pobieżne usystematyzowanie poglądów na temat motywów średniowiecznych oraz odnoszących się do feudalnejJaponii, które zaadaptowali twórcy serii, a także pozwoliła na wstępną weryfikację nielicznych opinii. O ile ogólne uwagi dotyczące recepcji niektórych motywów arturiańskich, modelu miłości dworskiej, obrazu średniowiecznego piekła czy tradycji, reguł oraz dziejów templariuszy i samurajów wydawały się uzasadnione, o tyle usilne poszukiwanie kompleksowych analogii okazało się błędne. Autorzy tych koncepcji wyszli z założenia, zgodnie z którym pewne obszary wiedzy zostały przeniesione do świata Gwiezdnych wojen właśnie en bloc. Taka perspektywa legła zapewne u podstaw zestawiania wszystkich głównych bohaterów sagi z postaciami oraz motywami arturiańskimi, które obserwujemy w publikacjach (w tym artykułach dostępnych w Internecie), oraz prób wtłaczania Jedi w sztywny i wszechobejmujący gorset samurajów lub rycerzy w habitach.

78 J. Man, dz. cyt.; sztuka walki mieczem japońskim również miała znaleźć odzwierciedlenie w świecie Gwiezdnych wojen, N. Jamilla, dz. cyt., s. 22-28; A.K. Puchalska, dz. cyt., s. 257.

79 Na temat kultu miecza, techniki jego wytwarzania, budowy, klasyfikacji oraz mitologii odnoszącej się do miecza: M. Wiatrak, dz. cyt., s. 16-39, 65-105.

80 A. Śpiewakowski, dz. cyt., s. 96-97. 


\section{BIBLIOGRAFIA}

\section{EKRANIZACJE}

Gwiezdne wojny: Część IV - Nowa nadzieja, George Lucas, USA 1977.

Gwiezdne wojny: Część V - Imperium kontratakuje, Irvin Kershner, USA 1980.

Gwiezdne wojny: Część VI - Powrót Jedi, Richard Marquand, USA 1983.

Gwiezdne wojny: Część I - Mroczne widmo, George Lucas, USA 1999.

Gwiezdne wojny: Część II - Atak klonów, George Lucas, USA 2002.

Gwiezdne wojny: Część III - Zemsta Sithów, George Lucas, USA 2005.

Gwiezdne wojny: Przebudzenie Mocy, J.J. Abrams, USA 2015.

\section{ŹRÓDŁA TEKSTOWE}

Alighieri Dante, Boska komedia (wybór), tłum. E. Porębowicz, wstęp K. Morawski, Wrocław 1977.

Miyamoto Musashi, Księga pięciu kręgów. Gorin no Sho, tłum. A. Żuławska-Umeda, Bydgoszcz 2010.

Miyamoto Musashi, The Complete Book of Five Rings, wyd. i tłum. K. Tokitsu, Boston-London 2010.

Opowieści Okragłego Stołu, oprac. J. Boulenger, tłum. K. Dolatowska, T. Komendant, wstęp E.D. Żółkiewska, Warszawa 1987.

Perry S., Gwiezdne wojny. Cienie imperium, tłum. J. Kotarski, Warszawa 1996.

Pieśn o Rolandzie, tłum. T. Boy-Żeleński, wstęp Z. Czerny, Warszawa 1981.

Platon, Dialogi, t. 1, thum. i wstęp W. Witwicki, Kęty 1999.

Undset S., Legendy o królu Arturze i Rycerzach Okragłego Stołu, tłum. B. Hłasko, Warszawa 1957.

\section{OBRAZY}

Bosch Hieronim, Ogród ziemskich rozkoszy, ok. 1503-1504, Museo Nacional del Prado, Madrid [w: Flemish \& Dutch Painting, ed. by B. Silvia, Bagno a Ripoli-Köln 2010, s. 123.

Bosch Hieronim, Siedem grzechów głównych, ok. 1475-1480, Museo Nacional del Prado, Madrid [w: Flemish \& Dutch Painting, ed. by B. Silvia, Bagno a Ripoli-Köln 2010, s. 114.

Bosch Hieronim, Wóz z sianem, ok. 1500-1502, Museo Nacional del Prado, Madrid [w: Flemish \& Dutch Painting, ed. by B. Silvia, Bagno a Ripoli-Köln 2010, s. 116.

Memling Hans, Sąd ostateczny, ok. 1467-1471, Muzeum Narodowe w Gdańsku [w: Flemish \& Dutch Painting, ed. by B. Silvia, Bagno a Ripoli-Köln 2010, s. 66. 


\section{OPRACOWANIA}

Aberth J., A Knight at the Movies: Medieval History on Film, New York 2003.

Ackerman D., Historia naturalna miłości, tłum. D. Gostyńska, Warszawa 1997.

Alexandridis A., Die Frauen des römischen Kaiserhauses. Eine Untersuchung ihrer bildlichen Darstellung von Livia bis Iulia Domna, Mainz 2004.

Bauer M., Templariusze. Mity i rzeczywistość, tłum. M. Słabicka, Wrocław 2003.

Bernau A., Bildhauer B., Medieval Film, Manchester 2011.

Biedermann H., Leksykon symboli, tłum. J. Rubinowicz, Warszawa 2001.

Bildhauer B., Filming the Middle Ages, London 2011.

Bogucka M., Gorsza płeć. Kobieta w dziejach Europy od antyku po wiek XXI, Warszawa 2005.

Bylina S., Wyobrażenie piekła w średniowiecznej Polsce (XIV-XV w.), „Polska Sztuka Ludowa. Konteksty” 1986, t. 40, z. 1-2, s. 97-102.

Cirlot J.E., Stownik symboli, tłum. I. Kania, Kraków 2000.

Classical Myth \& Culture in the Cinema, ed. by J. Solomon, Oxford 2001.

Classics and Cinema, ed. by M. Winkler, Lewisburg-London-Toronto 1991.

Demurger A., Jakub de Molay. Zmierzch templariuszy, tłum. M. Satora, Toruń 2012.

Elliott A., Remaking the Middle Ages: the Methods of Cinema and History in Portraying the Medieval World, Jefferson 2011.

Film and Fiction reviewing the Middle Ages, ed. by T. Shippey, Cambridge 2002.

Finke L.A., Shichtman M.B., Cinematic Illumination: the Middle Ages on Film, Baltimore 2010.

Głowiński M. i in., Stownik terminów literackich, Wrocław 1998.

Haydock N., Movie Medievalism: the Imaginary Middle Ages, Jefferson 2008.

Henthorne T., Boys to Men: Medievalism and Masculinity in "Star Wars" and "E.T.: The Extra-Terrestrial" [w: Medieval Hero on Screen: Representations from Beowulf to Buffy, ed. by M.W. Driver, Jefferson 2004, s. 73-93.

Hollywood and History. Costume Design in Film, hrsg. von E. Maeder, Los Angeles-London 1987.

Imperial Projections. Ancient Rome in Modern Popular Culture, ed. by S.R. Joshel, M. Malamud, D.T. McGuire, Baltimore 2001.

Jamilla N., Sword Fighting in the "Star Wars" Universe, Jefferson 2008.

Kuligowski W., Miłość na Zachodzie. Historia antropologiczna, Poznań 2004.

Lindner M., Rom und seine Kaiser im Historienfilm, Frankfurt am Main 2007. 
MacMullan T., Elegant Weapons for Civilized Ages: The Jedi and Warrior-Monks throughout History [w: ] Star Wars and History, ed. by N.R. Reagin, J. Liedl, Hoboken 2013, s. 67-98.

Medieval Hero on Screen: Representations from Beowulf to Buffy, ed. by M.W. Driver, Jefferson 2004.

Minois G., Historia piekła, tłum. A. Kędzierzawska, B. Szczepańska, Warszawa 1998.

Mittelalter im Film, hrsg. von Ch. Kiening, Berlin 2006.

Morgan G., The Holy Grail: From Antiquity to the Present Day, Harpenden 2015.

Ortega-Arjonilla E., Belén Martínez-López A., Looking for the Lost Paradise: Cultural Diversity, Translation and Film Adaptation in the Contemporary Dissemination of Medieval Culture, Stereotype and Values (Eco, Tolkien, Chrétien de Troyes, Follet and Lucas) [w: ] New Medievalisms, ed. by J. Martín-Párraga, J. de Dios Torralbo-Caballero, Cambridge 2015, s. 179-238.

Puchalska A.K., Bushidō. Ethos samurajów od opowieści wojennych do wojny na Pacyfiku, Bydgoszcz 2016.

Shaw S., Samurai Zen, Boston 1999.

Sokolski J., Staropolskie zaświaty. Obraz piekła, czyśćca i nieba w renesansowej i barokowej literaturze polskiej wobec tradycji średniowiecznej, Wrocław 1994.

Solomon J., The Ancient World in Cinema, New Haven-London 2001.

Śpiewakowski A., Samuraje, tłum. K. Okazaki, Warszawa 1989.

Turner A., Historia piekła, tłum. J. Jarniewicz, Gdańsk 1996.

Walker S., Higgs P., Cleopatra of Egypt: From History to Myth, Princeton 2001.

Weisl A.J., The Persistence of Medievalism: Narrative Adventures in Public Discourse, Basingstoke 2003.

Wenzel D., Kleopatra im Film. Eine Königin Ägyptens als Sinnbild für orientalische Kultur, Remscheid 2005.

Wiatrak M., Ideologia kultu samurajskiego miecza. Zarys obrazu w kulturze i spoŁeczeństwie dawnej Japonii, Oświęcim 2013.

\section{PUBLIKACJE DOSTĘPNE W INTERNECIE}

Are the Jedi based upon the Samurai? [online], 2014 [dostęp: 4 maja 2017]. Dostępny w World Wide Web: forums.obsidian.net/topic/14289-are-the-jedi-based-upon-the-samurai/.

Croft R, Medieval Literature and Star Wars, rozmowę przepr. M. Jung [online], 2014 [dostęp: 4 maja 2017]. Dostępny w World Wide Web: https://www.youtube. com/watch?v=8PDYdaRa_a4. 
Juliwitte, Star Wars Meets Arthuriana: Anakin and Padme [online], 2016 [dostęp: 4 maja 2017]. Dostępny w World Wide Web: https://clonecorridor.wordpress. com/2016/01/16/star-wars-meets-the-arthuriana-anakin-and-padme/.

Konieczny P, Star Wars and the Middle Ages [online], 2014 [dostęp: 4 maja 2017]. Dostępny w World Wide Web: www.medievalists.net/2014/03/star-wars-middle-ages/.

Man J., Sword vs. Lightsaber: How the Samurai Warriors inspired Jedi Knights [online], 2015 [dostęp: 4 maja 2017]. Dostępny w World Wide Web: www.salon. com $/ 2015 / 12 / 19 /$ sword_vs_lightsaber_how_the_samurai_warriors_inspired the_jedi_knights/.

Pahman D, The Jedi Knights Templar [online], 2016 [dostęp: 4 maja 2017]. Dostępny w World Wide Web: https://action.org/pub/commentary/2016/01/13/ jedi-knights-templar.

Star Wars/Arthurian Legend Comparison Tale [online], 2013 [dostęp: 4 maja 2017]. Dostępny w World Wide Web: www.angelfire.com/vi/knight_1192/SW/ SW_theories/SWAL.html.

Studying Skywalkers: Excalibur and the Lightsaber [online], 2016 [dostęp: 4 maja 2017]. Dostępny w World Wide Web: www.starwars.com/news/studying-skywalkers-excalibur-and-the-lightsaber.

Templariusze. Reguła, tłum. J. Lickiewicz, E. Zabrotowicz [online], 1998-2017 [dostęp: 4 maja 2017]. Dostępny w World Wide Web: www.templariusze.org/index. php?lang=pl\&grupa $=22 \&$ kategoria $=64$.

Williams W., Love and Star Wars: The Tragedy of Anakin and Padme [online], 2015 [dostęp: 4 maja 2017]. Dostępny w World Wide Web: www.thegeekblock.com/455/. 